\section{Experiential Philanthropy}

\author{
Chengxin-Michael $\mathrm{Xu}^{1}$, Huafang $\mathrm{Li}^{2}$ and \\ Lindsey M. McDougle ${ }^{1}$ \\ ${ }^{1}$ Rutgers, The State University of New Jersey, \\ Newark, NJ, USA \\ ${ }^{2}$ Grand Valley State University, Grand Rapids, \\ MI, USA
}

\section{Synonyms}

Student philanthropy

\section{Definition}

Experiential philanthropy is an innovative service-learning pedagogy in nonprofit management education. The pedagogy is intended to integrate academic learning with community engagement by allowing students an opportunity to study social problems and nonprofit organizations and then make decisions about directly or indirectly investing funds in them. Ultimately, experiential philanthropy is intended to teach students not only about issues associated with the management of nonprofit organizations but also about how to evaluate philanthropic responses to social issues.

\section{Introduction}

Experiential philanthropy is an innovative service-learning pedagogy that allows students to study nonprofit organizations and social problems and then directly or indirectly invest funds into nonprofits they believe are best able to solve the social problems they have learned about. This pedagogical approach aims to teach students not only about the theories and practices of nonprofits and philanthropy but also about how to evaluate philanthropic responses to social issues. Experiential philanthropy also aims to benefit nonprofit organizations by providing these organizations with critical resources and access to a potential supply of new and highly motivated donors. Given these dual aims, some scholars have begun to view experiential philanthropy as an important strategy to engage students in the learning process and connect them to communities.

This entry is on the topic of experiential philanthropy. The entry begins with a brief discussion of service-learning, which is the root of experiential philanthropy. Next, the topic of experiential philanthropy itself is introduced, followed by an overview of empirical evidence of its effectiveness on both students and communities. The entry then provides an overview of recent studies on experiential philanthropy and, finally, examines the potential for using experiential philanthropy as a pedagogic approach to public administration and public policy education. 


\section{Service-Learning: The Root of Experiential Philanthropy}

Before discussing experiential philanthropy as a pedagogic strategy, it is first important to provide an overview of service-learning - which is the root of experiential philanthropy.

\section{A Brief History of Service-Learning}

Service-learning is a teaching and learning strategy that integrates meaningful community service with instruction and reflection in order to enrich student learning experiences, teach civic responsibility, and strengthen communities. The concept of service-learning reflects the educational philosophy of John Dewey, who was a proponent of "progressive education" and believed that one of the most effective ways to acquire knowledge was through reflection on concrete situations and challenges.

On the basis of Dewey's educational philosophy, especially about how students absorb knowledge, many professional disciplines such as agriculture, engineering, and social work were among the first to implement service-learning activities into pedagogical practice. For example, the Michigan Agricultural College founded in 1857 was one of the earliest colleges to require that, as a condition of graduation, students participate in manual labor in the community for at least $3 \mathrm{~h}$ per day (Zieren and Stoddard 2004). This labor was often related to students' courses and their field of study.

Since this time, and in particular since the 1960s, service-learning has grown exponentially in higher education and is being incorporated into disciplines beyond merely those in professional domains (Zieren and Stoddard 2004). Indeed, service-learning has now become recognized as a key component of the curriculum in a multitude of degree programs. Today, most colleges and universities incorporate some form of servicelearning activity into their curriculums. These activities can range from one-time course requirements to semester-long service experiences.

\section{Key Empirical Contributions on the Topic of Service-Learning}

Over the years, there has been an abundance of research on service-learning. These studies have consistently shown that by connecting learners and communities, participation in servicelearning activities has a positive impact on student learning and development (Markus et al. 1993; Conway et al. 2009). Despite the abundance of service-learning research, though, prior to 2000 the majority of this research was descriptive. For example, many studies merely provided accounts of programmatic and course outcomes that did not rely on rigorous research designs (Eyler, Giles and Gray 1999). Therefore, these early studies often failed to clarify whether it was actually servicelearning that benefited students or whether other classroom- and student-level factors were at play.

Fortunately, service-learning research has become increasingly more sophisticated since this time. Indeed, there is now a broader and more complex array of studies assessing the value of, and mechanisms behind, servicelearning. Although this increase in research quality is good in terms of enhancing our understanding of the utility of service-learning, it is now difficult to pinpoint important contributions.

A survey of research on service-learning provides insights into emerging research trends on the topic of service-learning. Specifically, this section summarizes "hot topics" and associated findings based on the most frequently searched keywords as well as the most cited servicelearning according to research articles collected by Web of Science from 1983 to 2016.

The earliest study identified is a field experiment by Markus et al. (1993), which compared students participating in service-learning activities with those not participating in servicelearning activities. These researchers assessed differences in students' awareness of social problems as well as in their academic performance. They found strong empirical evidence of the effectiveness of community-based service-learning in a classroom setting.

Another key contribution to the servicelearning literature during this period was Barbara 
Jacoby's (1996) edited book, Service-Learning in Higher Education: Concepts and Practices, which provided a better understanding of how to practically develop and administer servicelearning initiatives. Indeed, Jacoby and colleagues provided frameworks for implementing service-learning and guidelines to determine successful implementation. Their work highlighted the need for faculty and administrators to make intentional linkages between community service activities and specific course-related learning and development outcomes.

A more recent contribution to the literature is from James Conway et al. (2009). In their work they relied on meta-analytic techniques to synthesize recent empirical studies on service-learning. After analyzing over 100 studies, Conway and colleagues found that service-learning has its largest effects on students' academic and social outcomes, and it has smaller effects on students' personal and citizenship outcomes. Additionally, they found that more structured, intensive, and longer duration service-learning activities tend to result in larger effects on student outcomes (Conway et al. 2009).

An examination on frequently cited keywords used in service-learning research from 1983 to 2016 helps to provide insights into important topics in the service-learning literature as well as emerging research trends. The largest group of research is community-centered service-learning and international service. On the one hand, this could indicate that most of the research on service-learning has focused on topics relating to community issues, both, domestically and internationally, which would certainly be consistent with the goals of service-learning. On the other hand, this could also indicate that despite research showing service-learning has its largest effects on students' academic and social outcomes, scholars have focused much of their research on assessing the effects of service-learning on communities.

Keywords of service-learning literature also show that it is now an important topic across disciplinary and geographic boundaries. Indeed, the literature labeled nursing education $\mid$ international service, which is the second largest and the most recent group of studies, suggests that service-learning is now being incorporated into various disciplines - including nursing education. "International service" is also frequently included among the top clusters, showing geographically broader adoption of service-learning in the context of an increasingly globalized society. In sum, this review of key studies and "hot topics" on service-learning provides an important foundational basis for the study and practice of experiential philanthropy.

\section{Experiential Philanthropy: A New and Innovative Service-Learning Pedagogy}

As a form of service-learning, experiential philanthropy focuses on educating students about nonprofit organizations and social issues. Experiential philanthropy encourages students to apply data collection techniques and critical thinking skills to better understand community needs and evaluate how nonprofits are meeting those needs; it then allows students to actively work toward improving their communities through the distribution of philanthropic funding. Thus, experiential philanthropy is believed to provide students with a better understanding of nonprofit management challenges - particularly those relating to fundraising, performance management, and grant making. For these reasons, experiential philanthropy has been well received within nonprofit management education.

By some estimates, there are currently more than 100 experiential philanthropy initiatives at colleges and universities across the USA (Stuart 2012); and, for the past decade, both the Once Upon a Time Foundation and the Learning by Giving Foundation - two of the nation's largest funders of experiential philanthropy - have contributed millions of dollars to support various forms of philanthropy-based education at US institutions of higher learning (Learning by Giving Foundation n.d; The Philanthropy Lab 2015).

In the remainder of this section, we provide a review of the goals of experiential philanthropy, various approaches to the implementation of experiential philanthropy initiatives, and empirical evidence on the effectiveness of experiential 
philanthropy as a pedagogic strategy within higher education.

\section{Goals of Experiential Philanthropy}

Similar to service-learning, many of the goals associated with experiential philanthropy relate to enhancing student learning outcomes and meeting community needs. However, experiential philanthropy differs from service-learning in that it may or may not involve an organized service component. In fact, unlike service-learning, experiential philanthropy is not intended to create greater service opportunities for students; it is intended to provide students with the opportunity to understand nonprofit management challenges and then assume the role of a philanthropic funding agent on behalf of their local community (Ahmed and Olberding 2007). Thus, experiential philanthropy is designed to teach students not only about abstract issues relating to nonprofit organizations and social issues but also about actual philanthropic decision-making processes. Not surprisingly, then, one of the most important goals of experiential philanthropy has been the cultivation of the next generation of philanthropists.

\section{Different Pedagogical Approaches to Experiential Philanthropy}

Experiential philanthropy can be implemented in several ways - however, two approaches have traditionally been most utilized: the direct approach and the indirect approach. The original approach, which is the direct approach, allows students an opportunity to engage in "direct giving." That is, this approach allows students to directly award funding to a nonprofit organization that they select. Students taking a course using this approach to experiential philanthropy are considered to be the direct, and final, decisionmakers of the funding awards.

In addition to the direct-giving approach, students can also act as indirect decision-makers in experiential philanthropy initiatives. With the indirect approach, instead of students awarding funds directly to nonprofit organizations, students are able to review and provide recommendations of grant proposals on behalf of a funding agency. The recommendations provided by the students are then taken into consideration in funding allocations; however, the agency is the ultimate funding decision-maker - not the students as in the direct approach. An advantage of the indirect giving approach is that, unlike the direct approach, instructors do not have to secure funding in order to engage in experiential philanthropy. However, securing relationships with funding agencies willing to allow students' access to grant proposals can still present challenges.

In general, both the direct and indirect approaches to experiential philanthropy reflect the essence of service-learning, which is to combine classroom knowledge with practical experience. In both approaches, students are expected to develop an understanding of social and community issues. Students are also expected to better understand nonprofit management challenges and the complexities of acquiring resources in the nonprofit sector.

\section{Effectiveness of Experiential Philanthropy}

Since the fundamental question to be asked of any educational program or initiative is "how are students affected?," it is important to understand whether experiential philanthropy (as with service-learning more generally) actually impacts student learning.

Enhancing academic and civic outcomes. Research on experiential philanthropy has shown that this type of service-learning pedagogy has largely positive effects in the classroom. One of the first studies to assess the effectiveness of experiential philanthropy relied on students' selfdescription of their experience participating in an experiential philanthropy course. Specifically, Renee Irvin (2005) used a case study approach to examine students' views about their directgiving experiential philanthropy project at the University of Oregon. The findings from this 
study indicated that after the experiential philanthropy project, students expressed an increased desire to get involved in volunteer and civic engagement activities in their community (Irvin 2005).

Ahmed and Olberding (2007) analyzed data from nearly 1000 university students who participated in an experiential philanthropy course and found that the majority believed that the course made them more aware of social problems and nonprofit organizations, increased their sense of responsibility to help others in need, and enhanced their intentions to give money and time to charity. In addition, Olberding (2009) found that students participating in an experiential philanthropy course reported enhanced understanding of course material.

The positive effects of experiential philanthropy have also been supported by recent quasiexperimental research. McDonald and Olberding (2012) in their quasi-experimental study of university students compared pre- and post-course evaluations from students who participated in an experiential philanthropy course with those who did not. Their findings indicated that similar to past research, at the end of the semester, students who participated in a course with an experiential philanthropy component were more aware of social problems and nonprofit organizations. These students also had stronger future intentions to participate in community service activities. These findings were also supported by qualitative data from their study.

Finally, a recent report by scholars at Brandeis University (2014) examined the effectiveness of several experiential philanthropy initiatives across the USA. In this report, these scholars found that students, regardless of university affiliation, gained greater philanthropic knowledge and skills through after their participation in an experiential philanthropy course (Benenson et al. 2014).

Which types of students benefit most from experiential philanthropy? Though experiential philanthropy has been shown to be a highly effective pedagogy, there is some evidence indicating that the positive effects of experiential philanthropy may differ by types of students. Ahmed and Olberding (2007), for instance, examined the experiences of students who participated in an experiential philanthropy course across majors and found that those majoring in the humanities and professional fields were more likely to indicate that the experiential philanthropy component of the course had no effect on their awareness of social problems and nonprofit organizations. These students were also more likely to indicate that the course had no effect on their belief in the value of experiential philanthropy or on their future intentions to become philanthropically involved in their communities. More recently, research has shown that certain types of students (such as females, older - in other words, nontraditional age - students, and students from helping profession majors) tend to report the most positive effects of experiential philanthropy (McDougle et al. 2017).

Long-term effects. A small handful of studies have shown that there are long-term effects associated with experiential philanthropy (Olberding and Hacker 2016). For instance, Ahmed and Olberding (2007) found that in 3- to 5-year follow-up surveys of students enrolled in a class with an experiential philanthropy component, nearly $86 \%$ of students indicated that they believed the class helped them to realize that they could make a difference in society and that they had a greater sense of personal responsibility in their community.

\section{Lessons from Nonprofit Management Education: Experiential Philanthropy as a Pedagogic Approach to Public Administration and Public Policy Education}

Although experiential philanthropy has primarily been used as a way to teach principles of nonprofit management, the findings from the research on experiential philanthropy indicate that the approach could be implemented more broadly particularly, within public administration and public policy education. Indeed, given that concerns about the social roles and responsibilities of higher education institutions have increasingly been on the rise (for a review, see Bryer 2014), 
complex societal challenges such as poverty, social inequality, environmental degradation, economic injustice, and human rights abuses have placed enormous expectations on colleges and universities to produce graduates who will not only have learned about these challenges but will also be able to help in solving many of them. As such, a number of schools of public administration and public policy have begun investing significant resources not only into educating and preparing students for professional careers but also into educating and preparing students to become civically engaged citizens - citizens who will ultimately be motivated to get involved in their local communities.

Given that experiential philanthropy combines classroom knowledge with real-world decisionmaking, this type of instruction can provide students of public administration and public policy with a better understanding of social issues in the public sphere. Given the interconnected nature of government and the nonprofit sector in addressing many of today's most pressing social issues, it will become increasingly more important for students of public administration and public policy to have greater knowledge of the challenges of managing nonprofit organizations.

More importantly, given the purpose of experiential philanthropy (not only to enhance the grant-making skills of students but also to cultivate future philanthropists who are committed to solving social problems), experiential philanthropy will likely provide students of public administration and public policy with an opportunity to demonstrate innovative problem-solving skills. Similar to service-learning, experiential philanthropy focuses on connecting students to communities, and the value of the pedagogy is reflected in the beneficial impacts that studies have shown that it has across many disciplines. As such, by incorporating experiential philanthropy into the curriculum of public administration and public policy education, students should be well equipped to identify pressing social needs in their communities and make strategic philanthropic contributions toward addressing those needs.
In the end, experiential philanthropy can provide students of public administration and public policy with greater knowledge of, and exposure to, issues beyond the traditional classroom setting - and at times even beyond students' own life experiences. This exposure can help these students to make important linkages between theory and practice, which can be particularly useful given that public managers must often be able to identify pressing community challenges, carefully weigh the available evidence, communicate findings to varied stakeholders, and successfully implement equitable solutions.

Moreover, given the pervasiveness of social problems, both domestically and abroad, this pedagogy could be used as a way to gain greater understanding of how philanthropy-based education can be used to address social problems across the globe. According to a recent report on philanthropy education in Europe, experiential philanthropy would be welcomed as an innovative approach to teaching about philanthropy and philanthropic responses to social issues in the country, but there is skepticism about the fundability of the pedagogy (Keidan et al. 2014).

\section{Conclusion}

Experiential philanthropy is an innovative educational approach for future nonprofit managers, philanthropists, and students of public administration and public policy. Indeed, by incorporating traditional classroom experiences with practical philanthropic investment and decision-making, students are encouraged to carefully consider how they go about solving social problems in their communities; and research has shown that this is an effective way to increase student learning and long-term civic interest.

\section{Cross-References}

Citizen Participation and Nonprofit Organizations

- Community Based Nonprofit Organizations

- Decision Making in Nonprofit Organizations 
- Giving and Volunteering

- Philanthropy and Nonprofit Organizations

\section{References}

Ahmed S, Olberding J (2007) Can student philanthropy help to address the current nonprofit identity crisis? A case study of a multiyear, multidisciplinary project at northern Kentucky university. J Public Aff Educ 13(3/4):593-615

Benenson J, Moldow E, Hahn A (2014) Engaging a new generation of philanthropists: findings from the pay it forward student philanthropy initiative. Retrieved from http://sillermancenter.brandeis.edu/PDFs/Engaging\% 20a\%20New\%20Generation\%20Exec\%20Sum.pdf

Bryer TA (2014) Higher education beyond job creation: universities, citizenship, and community. Lexington Books, Lanham

Conway JM, Amel EL, Gerwien DP (2009) Teaching and learning in the social context: a meta-analysis of service-learning's effects on academic, personal, social, and citizenship outcomes. Teach Psychol 36(4):233-245

Eyler J, Giles DE Jr (1999) Where's the learning in servicelearning? Jossey-Bass higher and adult education series. Jossey-Bass, Inc., San Francisco

Irvin RA (2005) The student philanthropists: fostering civic engagement through Grantmaking. J Public Aff Educ 11(4):315-324

Jacoby B (1996) Service-learning in higher education: concepts and practices, The Jossey-bass higher and adult education series. Jossey-Bass Publishers, San Francisco

Keidan C, Jung T, Pharoah C (2014) Philanthropy education in the UK and continental Europe: current provision, perceptions and opportunities. Retrieved from http:// www.cass.city.ac.uk/_data/assets/pdf_file/0004/2380 72/Final-Philanthropy-Education-revised.pdf

Markus GB, Howard JPF, King DC (1993) Integrating community service and classroom instruction enhances learning: results from an experiment. Educ Evavl Policy Anal 15(4):410-419

McDonald D, Olberding JC (2012) Learning by giving: a quasi-experimental study of student philanthropy in criminal justice education. J Crim Justice Educ 23(3):307-335. https://doi.org/10.1080/10511253. 2011.604339

McDougle L, McDonald D, Li H, McIntyre Miller W, Xu C (2017) Can philanthropy be taught? Nonprofit Volunt Sect Q 46(2):330-351. https://doi.org/10.1177/ 0899764016662355

Olberding JC (2009) Indirect giving to nonprofit organizations: an emerging model of student philanthropy. J Public Aff Educ 15(4):463-492

Olberding JC, Hacker W (2016) Does the "service" in service-learning go beyond the academic session? Assessing longer term impacts of nonprofit classes on community partners. J Nonprofit Educ Leadersh 6(1):25-46

Stuart E (2012) Teaching the art and science of philanthropy: Students learning to give. Desert News. Retrieved from http://www.deseretnews.com/article/ 765550297/Teach-the-art-and-science-of-philanthropyStudents-learning-to-give.html?pg=all

The Philanthropy Lab (2015) Who we are. Retrieved from https://www.thephilanthropylab.org/default.aspx

Zieren GR, Stoddard PH (2004) The historical origins of service-learning in the nineteenth and twentieth centuries: the transplanted and indigenous traditions. In: Speck BW, Hoppe SL (eds) Service-learning: history, theory, and issues. Praeger Publishers, Westport, pp 23-42 